\title{
Improvements in clinical characteristics of patients with non-alcoholic fatty liver disease, after an intervention based on the Mediterranean lifestyle: a randomised controlled clinical trial
}

\author{
Christina N. Katsagoni ${ }^{1}$, George V. Papatheodoridis ${ }^{2}$, Panagiota Ioannidou ${ }^{2}$, Melanie Deutsch ${ }^{3}$, \\ Alexandra Alexopoulou ${ }^{3}$, Nikolaos Papadopoulos ${ }^{3}$, Maria-Vasiliki Papageorgiou ${ }^{2}$, \\ Elizabeth Fragopoulou ${ }^{1}$ and Meropi D. Kontogianni ${ }^{1 *}$ \\ ${ }^{1}$ Department of Nutrition E Dietetics, School of Health Sciences and Education, Harokopio University, 70 El. Venizelou str., \\ 17671 Athens, Greece \\ ${ }^{2}$ Department of Gastroenterology, Medical School of National and Kapodistrian University of Athens, Laiko General Hospital \\ of Athens, 17 Agiou Thoma str., 11527 Athens, Greece \\ ${ }^{3} 2^{\text {nd }}$ Department of Internal Medicine, Medical School of National and Kapodistrian University of Athens, Hippokration \\ General Hospital of Athens, 114 Vassilissis Sophias Avenue, 11527 Athens, Greece
}

(Submitted 12 January 2018 - Final revision received 21 March 2018 - Accepted 13 April 2018)

\section{Abstract}

Lifestyle interventions remain the cornerstone therapy for non-alcoholic fatty liver disease (NAFLD). This randomised controlled single-blind clinical trial investigated the effect of Mediterranean diet (MD) or Mediterranean lifestyle, along with weight loss, in NAFLD patients. In all, sixty-three overweight/obese patients (50 (SD 11) years, BMI $=31.8$ (SD 4.5$) \mathrm{kg} / \mathrm{m}^{2}, 68 \%$ men) with ultrasonography-proven NAFLD (and elevated alanine aminotransferase (ALT) and/or $\gamma$-glutamyl transpeptidase (GGT) levels) were randomised to the following groups: (A) control group (CG), (B) Mediterranean diet group (MDG) or (C) Mediterranean lifestyle group (MLG). Participants of MDG and MLG attended seven 60-min group sessions for 6 months, aiming at weight loss and increasing adherence to MD. In the MLG, additional guidance for increasing physical activity and improving sleep habits were given. Patients in CG received only written information for a healthy lifestyle. At the end of 6 months, $88.8 \%$ of participants completed the study. On the basis of intention-to-treat analysis, both MDG and MLG showed greater weight reduction and higher adherence to MD compared with the CG (all $P<0.05)$ at the end of intervention. In addition, MLG increased vigorous exercise compared with the other two study groups $(P<0 \cdot 001)$ and mid-day rest/naps compared with CG $(P=0 \cdot 04)$. MLG showed significant improvements in ALT levels (i.e. ALT $<40 \mathrm{U} / 1(P=0 \cdot 03)$ and $50 \%$ reduction of ALT levels $(P=0 \cdot 009))$ and liver stiffness $(P=0.004)$ compared with CG after adjusting for \% weight loss and baseline values. MDG improved only liver stiffness compared with CG $(P<0.001)$ after adjusting for the aforementioned variables. Small changes towards the Mediterranean lifestyle, along with weight loss, can be a treatment option for patients with NAFLD.

Key words: Non-alcoholic fatty liver disease: Mediterranean diet: Mediterranean lifestyle: Weight loss: Sleep: Intervention

Non-alcoholic fatty liver disease (NAFLD) and non-alcoholic steatohepatitis (NASH) are the most prevalent liver disorders in Western countries $^{(1)}$. NAFLD patients are at a high risk of developing metabolic syndrome, type 2 diabetes mellitus $(\mathrm{T} 2 \mathrm{DM})^{(2)}$ and cardiovascular disorders ${ }^{(3)}$. Indeed, NAFLD is associated with increased overall, as well as liver-related, mortality compared with the healthy population ${ }^{(4)}$. The 'multiple hit' hypothesis, including hits such as insulin resistance, lipotoxicity, nutritional factors, gut microbiota, genetic and epigenetic factors, is currently the most widely accepted theory for NAFLD pathogenesis ${ }^{(5)}$.
At present, no formally approved pharmacological or surgical therapy exists for the management of NAFLD or NASH, and lifestyle modifications remain the cornerstone therapy ${ }^{(6)}$. A 7-10\% weight loss results in improvements in liver enzymes and histology, and can be achieved either by dietary changes or by adopting an active lifestyle ${ }^{(1)}$. Exercise alone has also been shown to improve intrahepatic lipid content, independent of weight loss ${ }^{(7)}$ and baseline $\mathrm{BMI}^{(8,9)}$, whereas the existing evidence regarding the optimal diet composition for NAFLD remains conflicting ${ }^{(7,10)}$.

Mediterranean diet (MD) is a dietary pattern widely known for its favourable effects, mainly in relation to mortality, CVD

Abbreviations: ALT, alanine aminotransferase; AST, aspartate aminotransferase; CG, control group; GGT, $\gamma$-glutamyl transpeptidase; LSM, reliable liver stiffness measurements; MD, Mediterranean diet; MDG, Mediterranean diet group; MET, metabolic equivalents; MLG, Mediterranean lifestyle group; NAFLD, nonalcoholic fatty liver disease; NFS, NAFLD fibrosis score.

* Corresponding author: Assistant Professor M. D. Kontogianni, fax +30 210 9549141, email mkont@hua.gr 
risk factors, cancer ${ }^{(11)}$, $\mathrm{T}_{2} \mathrm{DM}^{(12)}$ and risk of metabolic syndrome ${ }^{(13)}$. Moreover, evidence from limited epidemiological data indicates that greater adherence to the MD is associated with lower probability of having $\mathrm{NASH}^{(14)}$ or metabolic syndrome in NAFLD patients ${ }^{(15)}$. Although data from interventional studies are sparse, in the uncontrolled clinical trial of Trovato et $a l^{(16)}$ adherence to the MD was associated with improvements in liver fat content. Accordingly, in the cross-over clinical trial of Ryan et al. ${ }^{(17)}$, increased adherence to the MD was associated with reduced intrahepatic lipid as assessed by magnetic resonance spectroscopy ( $\left.{ }^{1} \mathrm{H}-\mathrm{MRS}\right)$, improved insulin sensitivity and fibrosis compared with a low-fat/high-carbohydrate controlled diet, under conditions of weight maintenance. Recently, the potential additional effects of other aspects of the Mediterranean lifestyle (i.e. adequate sleep and physical activity) have been discussed in the more recent version of the MD pyramid ${ }^{(18)}$

Given the small number of interventional studies focused on the effects of MD in NAFLD, the present study aimed at exploring the potential benefits of an intervention based on the MD per se or the Mediterranean lifestyle, along with weight loss, on clinical and laboratory characteristics (i.e. liver enzymes and liver stiffness) of ultrasound-proven NAFLD patients, compared with usual care.

\section{Methods}

\section{Study design}

The present study was a randomised, controlled single-blind clinical trial. Eligible participants were randomly assigned for 6 months to one of the following three groups: (A) control group (CG), (B) Mediterranean diet group (MDG) or (C) Mediterranean lifestyle group (MLG). The randomisation was made using a random numbers system. Each patient was fully informed about the goals and procedures of the study and provided a written consent before enrolment. The recruitment, allocation and intervention of the study were conducted from May 2013 to June 2016. The study was carried out in accordance with the regulations of EU directive 28/2005/EC for clinical trials and was approved by the Bioethics Committee of 'Harokopio University'. The study was also registered in the American National Health Institute records (ClinicalTrials.gov, ID: NCT01894438). Moreover, the study protocol was designed in compliance with the CONSORT (Consolidated Standards of Reporting Trials) 2010 statement $^{(19)}$.

\section{Study participants}

Consecutive NAFLD patients were recruited from two outpatient liver clinics (Academic Department of Gastroenterology, Laiko General Hospital of Athens, Greece, and $2^{\text {nd }}$ Academic Department of Internal Medicine, Hippokration General Hospital of Athens, Greece) (see Fig. 1). The inclusion criteria of this study were as follows: (a) age 18-65 years, (b) BMI $25-40 \mathrm{~kg} / \mathrm{m}^{2}$ and (c) NAFLD diagnosis based on the following criteria: elevated alanine aminotransferase (ALT) and/or $\gamma$-glutamyl-transpeptidase (GGT) levels, evidence of hepatic

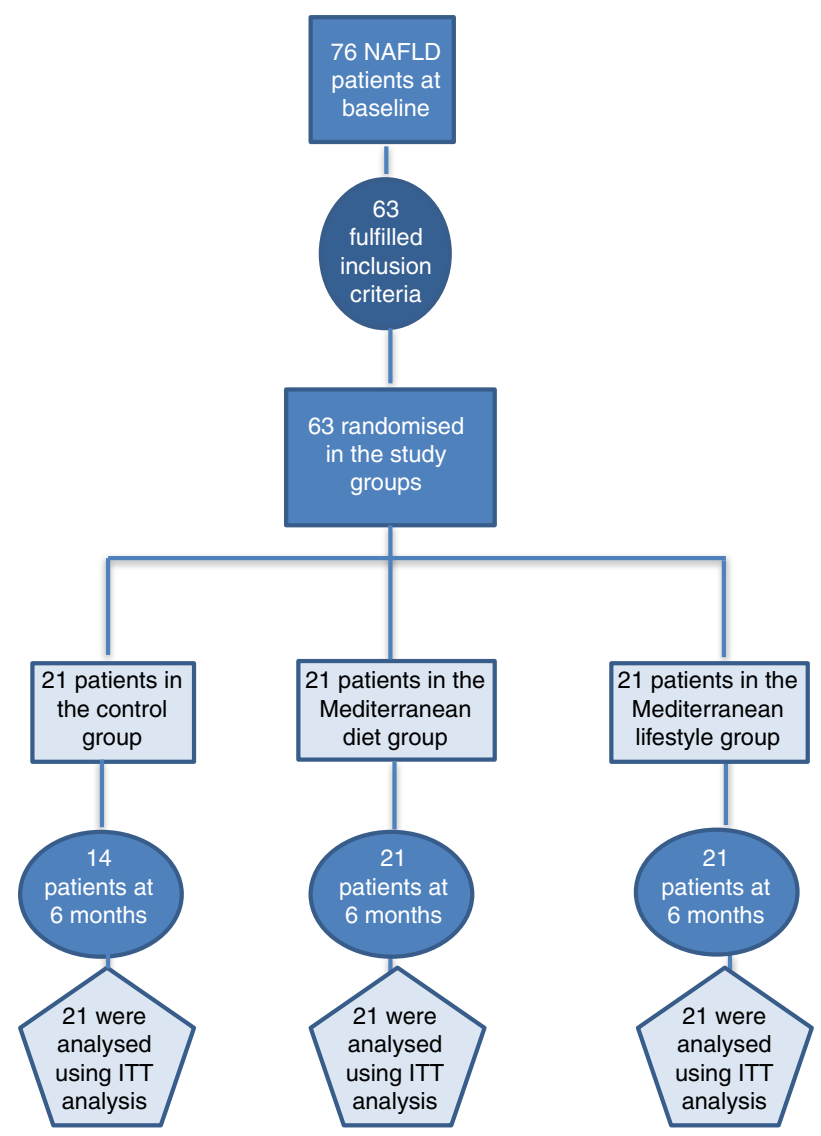

Fig. 1. Flow chart of the current clinical trial. NAFLD, non-alcoholic fatty liver disease; ITT: Intention-to-treat analysis.

steatosis on ultrasound and/or compatible liver histology and no other causes of liver injury or steatosis. Patients with positive serological markers for hepatitis B (HBsAg), hepatitis C (antiHCV) and HIV (anti-HIV), weekly alcohol consumption more than $210 \mathrm{~g}$ for men or $140 \mathrm{~g}$ for women, use of potentially hepatotoxic or steatogenic agents (i.e. amiodarone, valproate, glucocorticosteroids, tamoxifen, methotrexate and other chemotherapeutic agents), evidence of metabolic or autoimmune liver disease, diabetes or the presence of known systemic disease with potential liver involvement were excluded. History of alcohol intake was taken from the patients and was confirmed by the patients' relatives or friends. Participants who were already on a weight-loss diet were excluded from the study.

\section{Dietary intervention and monitoring}

At baseline, all three groups were given an indicative energy restriction regimen with similar percentage of macronutrients, namely $45 \%$ carbohydrates, $20 \%$ protein and $35 \%$ lipids, which provided $6276 \mathrm{~kJ}$ ( $1500 \mathrm{kcal})$ for women and $7531 \mathrm{~kJ}$ (1800 kcal) for men. The CG received also general written dietary guidelines for a healthy lifestyle at baseline, without any other intervention until the end of the 6-month period (online Supplementary eTable 1S). Participants in MDG and MLG followed a more intensive counselling programme, consisting of seven 60-min small group sessions (three to five people), held every 
2 weeks for the first 2 months and every month for the next 4 months, co-ordinated by a research dietitian (C. N. K.). Nutritional counselling was based on the goal-setting theory ${ }^{(20)}$ aiming at improving diet quality and promoting energy restriction by enhancing adherence to the Mediterranean food pattern, as described in the MD pyramid ${ }^{(18)}$ and the Dietary Guidelines for Greeks ${ }^{(21)}$ (online Supplementary eTable 2S). In the MDG, no further instructions were given for other lifestyle parameters. In the MLG, goals were also set for enhancing activity through a moderate-vigorous intensity physical activity programme of at least $30 \mathrm{~min} / \mathrm{d}$ (fast or very fast walking, slow or fast running, dancing, tennis and so on), as well as for optimal sleep duration (i.e. $\geq 7$ and $\leq 9 \mathrm{~h} / \mathrm{d}$ ) ${ }^{(22)}$ and mid-day rest (e.g. naps, siesta) (online Supplementary eTable 3S).

In MDG and MLG, compliance to the goals was checked using self-monitoring methods. In particular, multiple selfmonitoring tools were used, namely special forms according to intervention goals or 3-d dietary records. At each session, patients discussed with the researcher-dietitian any possible barriers encountered while trying to achieve the goals. To selfmonitor physical activity, volunteers in the MLG only were given a pedometer (TANITA Step ${ }^{\text {TM }}, 3$ Axes Pedometer, PD724; TANITA Europe $\mathrm{GmbH}$ ) and aimed at a gradual increase in steps, with the ultimate goal of 10000 steps/d. Participants not attending three consecutive sessions were considered as dropouts.

\section{Anthropometric and demographic characteristics}

Height of patients was measured once with a Seca type measuring tape with $\pm 0.5 \mathrm{~m}$ accuracy. Body weight of patients was measured using a digital scale with $\pm 100 \mathrm{~g}$ accuracy, barefoot and under the same conditions in each time point of the study (baseline and at the end of the study). BMI was calculated as the weight ratio (in $\mathrm{kg}$ ) to the square of the height (in $\mathrm{m}^{2}$ ). Obesity was defined as BMI $\geq 30 \mathrm{~kg} / \mathrm{m}^{2}$. Waist circumference (WC) was calculated on the average between the 12 th rib and the iliac crest, with $\pm 0 \cdot 1 \mathrm{~m}$ accuracy. Increased (abnormal) WC was defined as $>88$ and $>102 \mathrm{~cm}$ for women and men, respectively.

Those who smoked at least one cigarette a day were defined as smokers, those who had stopped smoking before their enrolment were defined as former smokers and those who had not smoked a single cigarette during their life were defined as non-smokers. The educational level of the participants was determined by years of education. In addition, information on marital status (married, unmarried, divorced or widowed), the number of children/family members and the area of residence (urban or rural) was recorded.

\section{Assessment of dietary intake}

Participants' dietary habits over the last 6 months were assessed at baseline and at the end of the intervention period using a semi-quantitative sixty-nine-item FFQ validated for the Greek population $^{(23)}$ and two 24-h recalls. On the basis of the FFQ, consumption of main food groups such as total, low-fat and fullfat dairy products; total, refined and non-refined cereals and products; and red meat, poultry, fish, legumes, vegetables, fruit, sweets, soft drinks and nuts were calculated in servings per day as described in the dietary guidelines for Greek adults ${ }^{(21)}$. Adherence to the MD was assessed using MedDietScore ${ }^{(24)}$. The 24-h recalls were based on the five-step method of the US Department of Agriculture ${ }^{(25)}$. Two 24-h recalls were implemented twice during the study (at baseline and at 6 months), one via telephone and one face to face with the patient. The data from the recalls were analysed for energy and macronutrient intake using Nutritionist Pro software, version 2.2 (Axxya Systems).

\section{Physical activity assessment}

The Athens Physical Activity Questionnaire (APAQ) ${ }^{(26)}$, which is validated for the Greek population, was used to determine participants' physical activity level (PAL). The APAQ was filled by all subjects twice during the study evaluations (at the beginning and at 6 months), asking participants to record a typical week of their life. Physical activity was also recorded at every session in the MLG, to check compliance to activity relevant goals. Total PAL was determined by measuring the total metabolic units (MET) expended per minute per day (MET-min/d). Total MET-min/d were calculated separately for low, moderate and vigorous exercise. Moreover, total duration of sedentary activities at leisure time was estimated. Sedentary activities were defined as all activities with total MET $\leq 1 \cdot 5^{(27)}$, such as watching $\mathrm{TV}$, video games, reading and so on, without taking sleep into account.

\section{Sleep duration and quality assessment}

Evaluation of sleep habits was performed both at baseline and at 6 months. Habitual total night sleep hours and mid-day rest/ naps (siesta) (yes/no) were self-reported and recorded. Sleep quality was assessed using an appropriate sleep scale questionnaire (Athens Insomnia Scale) ${ }^{(28)}$. Optimal sleep duration was defined as sleep duration $\geq 7$ and $\leq 9 \mathrm{~h} / \mathrm{d}^{(22)}$.

\section{Biochemical and clinical parameters}

Blood samples were collected between 08.30 and 10.00 hours, after $12 \mathrm{~h}$ of fasting. Serum and plasma were isolated and frozen immediately at $-80^{\circ} \mathrm{C}$. Glucose levels, albumin, total cholesterol (TC), TAG and HDL-cholesterol were measured by enzymatic colorimetric assay (COBAS ${ }^{\circledR} 8000$ analyzer; Roche), whereas the LDL-cholesterol concentrations were calculated using the Friedewald formula ${ }^{(29)}$. Non-HDL (determined by TC minus HDL-cholesterol), as well as the ratio of TAG:HDL-cholesterol, were calculated. Insulin levels were determined by chemiluminescence method (E170 modular analyzer; Roche) and then homoeostasis model assessment of insulin resistance (HOMA-IR) was calculated using the formula of Matthews et al. ${ }^{(30)}$. Levels of liver enzymes, namely ALT, aspartate aminotransferase (AST) and GGT, were measured by enzymatic colorimetric method (COBAS ${ }^{\circledR} 8000$ analyzer). Normal ALT concentration was defined as ALT $<40 \mathrm{U} / 1$, whereas normal GGT concentration was defined as GGT $<30 \mathrm{U} / 1$.

Blood pressure was measured at baseline and at the 6-month reassessment in the right hand, with patient resting in a sitting position, after having calmed down in a quiet environment. 
Hypertension was defined as systolic blood pressure $\geq 140 \mathrm{mmHg}$ and/or diastolic blood pressure $\geq 90 \mathrm{mmHg}$ or reception of anti-hypertensive drugs.

\section{Non-invasive methods for detection of fibrosis}

NAFLD fibrosis score (NFS) was calculated according to Angulo et $a{ }^{(31)}$ formula using six variables: age, BMI, presence of hyperglycaemia (fasting blood glucose $\geq 110$ ) or previously diagnosed T2DM, AST:ALT ratio, platelet count and albumin levels. NFS $>0.676$ is associated with the presence of significant fibrosis, whereas $<-1.455$ is associated with the absence of fibrosis. NFS scores between -1.455 and 0.675 are referred as 'indeterminate' scores ${ }^{(31)}$.

\section{Shear-wave elastography}

Reliable liver stiffness measurements (LSM) (in $\mathrm{kPa}$ ) were performed in all patients both at baseline and at 6 months by twodimensional shear-wave elastography of the liver by the same clinician. LSM were operated using the Aixplorer ${ }^{\circledR}$ MultiWave $^{\mathrm{TM}}$ ultrasound system (SuperSonic Imagine S.A.) with the single crystal curved probe at frequencies of $1-6 \mathrm{MHz}$. The examination was considered to be reliable if at least five valid measurements were obtained based on good sonographic signal, combined with $<25 \%$ ratio of SD:mean LSM (mean value of all valid measurements per examination). Patients were categorised on the basis of their LSM results, as reviewed by Abenavoli et al $^{(32)}$, into those with LSM $>6.6$ and LSM $\leq 6.6 \mathrm{kPa}$, suggesting the presence or not of significant fibrosis, respectively.

\section{Study primary and secondary outcomes}

The primary end point of the present study was clinically significant decrease in ALT levels defined as the restoration of ALT within normal limits (i.e. ALT $<40 \mathrm{U} / \mathrm{l}$ ) or at least $50 \%$ decrease of its initial levels. The secondary end points included the restoration of GGT levels within normal limits (i.e. GGT $<30 \mathrm{U} / 1$ ), significant improvements in liver stiffness (i.e. LSM $\leq 6 \cdot 6 \mathrm{kPa}$ ) and changes in NFS scores.

\section{Statistical analysis}

On the basis of data from previously published research ${ }^{(14,33)}$, it was assumed that primary end point could be achieved in $50 \%$ of patients in the intense dietary intervention groups and $10 \%$ in the CG. Hence, it was estimated that twenty-one patients were needed per treatment group (including $10 \%$ of patients who might be lost to follow-up) to find statistically significant difference from the CG (with 5 and $20 \%$ statistical type I and II error and $80 \%$ statistical power, respectively).

Continuous variables are presented as means and standard deviations, whereas continuous skewed variables as medians and interquartile ranges. Qualitative categorical variables are presented as absolute $(n)$ and relative frequencies (\%). The normality of variables was checked through Shapiro-Wilk test and graphically through histograms.

The primary analyses were performed in the intentionto-treat (ITT) population, which included all patients who were randomly assigned to a study group (i.e. including dropouts from the CG, $n 7 / 21,33 \%$ ). Missing values were imputed using multiple imputation (MI), which involved fitting a statistical model to the observed data with the use of missing-at-random $\operatorname{method}^{(34)}$. For the analysis of the primary end points as continuous variables, the three study groups were compared by means of ANCOVA, with study group assignment as fixed effect and \% weight loss and baseline value of the dependent variable as covariates. Skewed variables were log-transformed for the analyses and are presented in their anti-logarithm form.

Categorical changes for dichotomous end points were analysed with the use of logistic regression with the same fixed effects and covariates as the respective ANCOVA analysis. For secondary analyses, missing data were imputed according to MI, whereas ANCOVA and logistic regression were also used. Sensitivity analyses (per protocol analyses) were also performed to assess the robustness of the primary analysis.

A two-sided $\alpha$ level of $5 \%$ was used to indicate statistical significance. CI, when calculated, were 95\% CI. Bonferroni correction was used for pairwise comparisons among the three study groups. Analyses were performed using the statistical package SPSS (version 23.0 for Windows; SPSS 2015).

\section{Results}

In all, twenty-one participants were allocated to each group. All patients from MDG and MLG successfully completed the 6-month follow-up evaluation (100\%). No harms or unintended side effects were reported by participants. Patients' adherence to the intense intervention groups, as assessed by their participation in the group sessions and the 6-month evaluation appointment, was also $100 \%$. Seven participants from the CG (33\%) were considered as dropouts as they did not complete the 6-month evaluation. Dropouts had higher LSM $(P=0.025)$ and a trend for higher BMI levels $(P=0.067)$ compared with patients from CG who successfully completed the study (data not shown). Baseline characteristics of all participants according to their allocation to study groups are shown in Table 1.

Regarding lifestyle characteristics, both MDG and MLG significantly reduced hours of sedentary activities during leisure time compared with CG, after adjusting for baseline values (Table 2). Nevertheless, at the end of the intervention, only MLG significantly increased levels of vigorous exercise, compared with the other two study groups $(P<0 \cdot 001)$, with no other significant differences in MET-min per day or PAL (Table 2). No significant differences were recorded among groups regarding habitual sleep hours $(P=0 \cdot 41)$ and optimal sleep duration $(P=0 \cdot 87)$. However, at the end of the intervention, mid-day rest/naps (siesta) differed significantly in the MLG compared with the CG, after adjusting for baseline values (Table 2). Moreover, although no significant differences were noticed in sleep hours among groups at the end of the study, patients in MLG improved the relative low sleep hours $(P=0.03)$ during intervention, whereas daytime sleepiness compared with the GG was also improved $(P=0 \cdot 02)$ (data not shown).

Furthermore, all three study groups significantly reduced their energy intake, as estimated from 24-h recalls (Table 2). 
Table 1. Descriptive statistics of non-alcoholic fatty liver disease patients in each study group at baseline (Numbers and percentages; medians and interquartile ranges (IQR, 25th-75th))

\begin{tabular}{|c|c|c|c|c|c|c|c|}
\hline \multirow[b]{2}{*}{ Variables } & \multicolumn{2}{|c|}{ CG $(n 21)$} & \multicolumn{2}{|c|}{ MDG ( $n$ 21) } & \multicolumn{2}{|c|}{ MLG ( $n$ 21) } & \multirow[b]{2}{*}{$P^{\star} \dagger$} \\
\hline & $n$ & $\%$ & $n$ & $\%$ & $n$ & $\%$ & \\
\hline Sex (males) & 13 & 61.9 & 13 & 61.9 & 17 & 81 & 0.31 \\
\hline Age (years) & & & & & & & 0.90 \\
\hline Median & \multicolumn{2}{|c|}{47} & \multicolumn{2}{|c|}{44} & \multicolumn{2}{|c|}{48} & \\
\hline IQR & \multicolumn{2}{|c|}{$42-60$} & \multicolumn{2}{|c|}{$41-60$} & \multicolumn{2}{|c|}{$38-60$} & \\
\hline Education (years) & & & & & & & 0.95 \\
\hline Median & \multicolumn{2}{|c|}{16} & \multicolumn{2}{|c|}{16} & \multirow{2}{*}{\multicolumn{2}{|c|}{$\begin{array}{c}16 \\
12-16.5\end{array}$}} & \\
\hline IQR & \multicolumn{2}{|c|}{$12-16 \cdot 5$} & \multicolumn{2}{|c|}{$12-16$} & & & \\
\hline Smoking (yes) & 3 & $14 \cdot 3$ & 5 & $23 \cdot 8$ & 5 & 23.8 & 0.67 \\
\hline Marital status (married) & 15 & 71.4 & 20 & $95 \cdot 2$ & 13 & 61.9 & 0.10 \\
\hline \multicolumn{7}{|l|}{ Residence } & 0.39 \\
\hline Urban & 16 & $76 \cdot 2$ & 16 & $76 \cdot 2$ & 19 & 90.5 & \\
\hline Semi-urban & 5 & $23 \cdot 8$ & 5 & $23 \cdot 8$ & 2 & 9.5 & \\
\hline
\end{tabular}

CG, control group; MDG, Mediterranean diet group; MLG, Mediterranean lifestyle group.

* Statistical significance $(P)$ was set at $P<0.05$.

† Comparisons between categorical variables were made using the $\chi^{2}$ test, and between continuous variables with the Kruskal-Wallis $\mathrm{H}$ test.

No differences were recorded in macronutrient intake between the three study groups. However, only the MDG increased PUFA and MUFA intake, whereas both intensive intervention groups increased dietary fibre intake compared with the CG, after adjusting for baseline values (Table 2). Moreover, both MDG and MLG significantly increased their adherence to the $\mathrm{MD}$, as assessed by MedDietScore, compared with the CG, with no significant differences between the two intensive intervention groups (mean difference 1.6; 95\% CI -1.4, 4.7), after controlling for baseline values (Table 2 ). On a food group basis, both MDG and MLG significantly increased consumption of whole grains, fruit, vegetables and nuts, and significantly reduced the intake of refined cereals, potatoes, red meat and sweets (all $P<0 \cdot 05$, online Supplementary eTable 4S).

Regarding anthropometric changes, MDG and MLG showed greater weight loss $(P=0.01)$ and BMI reductions $(P=0.008)$ compared with the CG, which also showed a slight body weight reduction (Table 2). Nevertheless, improvements in anthropometric characteristics were similar among MDG and MLG ((\% weight loss: mean difference $-0 \cdot 85 ; 95 \% \mathrm{CI}-0.45,1.6$ and $\mathrm{BMI}=-1 \cdot 01 ; 95 \% \mathrm{CI}-0 \cdot 97,1 \cdot 05)$.

Regarding the study primary outcomes (i.e. ALT $<40 \mathrm{U} / 1$ and $50 \%$ reduction of ALT levels) based on the ITT analyses, MLG showed significant improvements compared with the CG at the end of intervention (Table 3) after adjusting for baseline values and \% weight loss. In contrast, MDG did not show significant changes in the primary outcomes. Regarding the secondary outcomes, neither MDG nor MLG showed changes in GGT levels or NFS, but both improved liver stiffness compared with the CG, after adjusting for baseline values and \% of weight loss (Table 3). Between the intensive intervention groups, no differences were noticed regarding the study's primary and secondary outcomes, except that patients in the MLG tended to have higher likelihood of halving their ALT levels compared with MDG (OR $=0.27 ; 95 \%$ CI 0.07, 1.03), after controlling for baseline values and \% weight loss. No differences among groups were observed regarding HOMA-IR, even after adjusting for weight loss. Patients in the MDG significantly improved LDL and non-HDL after adjusting for baseline values and \% weight loss (Table 4). No significant improvements in lipid profile were observed in the MLG. As far as blood pressure is concerned, no significant differences were observed between groups regarding systolic $(P=0.59)$ and diastolic $(P=0.57)$ blood pressure.

According to the per-protocol analyses, the percentage of weight loss was lower in CG (median $-0.9 \%$ (interquartile range $-3 \cdot 4,0 \cdot 79)$ ) compared with intensive care groups, and therefore differences between groups regarding \% weight loss $(P=0.024)$ were maintained (data not shown). Moreover, vigorous exercise remained significantly different between MLG and CG $(P=0 \cdot 01)$, as well as between the intensive care $(P=0.05)$. Adherence to the MD (as assessed by MedDietScore) increased in both MDG $(P=0.005)$ and MLG $(P<0.001)$ compared with CG, with no differences between intensive care groups $(P=0.67)$, after adjusting for baseline values. In regard to the main outcomes, changes in ALT levels (i.e. ALT <40 U/1 $(P=0.05)$ and $50 \%$ reduction of ALT levels $(P=0.047))$, as well as liver stiffness $(P=0.02)$, remained significant in the MLG compared with CG, after adjusting for \% weight loss and baseline values. However, non-significant trends were observed in the MDG (i.e. $P$ for $50 \%$ reduction in $\mathrm{ALT}=0.09$ and $\mathrm{P}$ for liver stiffness $=0.17$ ), after adjusting for \% weight loss and baseline values.

\section{Discussion}

The present randomised controlled single-blind clinical trial aimed to investigate the potential beneficial effects of the MD per se or the Mediterranean lifestyle (targeting also at adequate sleep and exercise), along with weight loss, on clinical and laboratory characteristics of ultrasonography-diagnosed NAFLD patients compared with usual care. According to the results, the MLG significantly improved ALT levels (i.e. ALT normalisation and ALT reduction to half levels), as well as liver stiffness, compared with the CG, and these effects remained significant after adjustment for weight loss. In the MDG, only liver stiffness improvements remained significant after adjusting for weight loss.

Any existing recommendations regarding NAFLD treatment, before or in addition to pharmacological or surgical therapeutic 
Nes British Journal of Nutrition

Table 2. Intervention effects on lifestyle characteristics in the intention-to-treat population

(Medians and interquartile ranges (IQR, 25th-75th); mean values and standard deviations; adjusted differences and $95 \%$ confidence intervals; numbers and percentages)

\begin{tabular}{|c|c|c|c|c|c|c|c|c|c|c|c|c|c|c|c|c|c|}
\hline & \multicolumn{4}{|c|}{$\mathrm{CG}(n 21)$} & \multicolumn{4}{|c|}{ MDG $(n 21)$} & \multicolumn{4}{|c|}{ MLG $(n 21)$} & \multirow[b]{3}{*}{$P^{*}$} & & & \multirow{2}{*}{\multicolumn{2}{|c|}{ MLG v. CG }} \\
\hline & \multicolumn{2}{|c|}{ Baseline } & \multicolumn{2}{|c|}{6 months } & \multicolumn{2}{|c|}{ Baseline } & \multicolumn{2}{|c|}{6 months } & \multicolumn{2}{|c|}{ Baseline } & \multicolumn{2}{|c|}{6 months } & & \multicolumn{2}{|c|}{ MDG $v . \mathrm{CG}$} & & \\
\hline & Median & IQR & Median & IQR & Median & IQR & Median & IQR & Median & IQR & Median & IQR & & $\begin{array}{l}\text { Adjusted } \\
\text { difference }^{\star *}\end{array}$ & $95 \% \mathrm{Cl}$ & $\begin{array}{l}\text { Adjusted } \\
\text { difference }^{* *}\end{array}$ & $95 \% \mathrm{Cl}$ \\
\hline $\begin{array}{l}\text { MedDietScore } \\
(0-55)\end{array}$ & 30 & $27-34$ & 32 & 29-35 & 32 & $30-34$ & 38 & $34-41$ & 35 & $32-37$ & 40 & $38-42$ & $<0.001 \dagger$ & $5 \cdot 3 \dagger$ & $2 \cdot 3,8 \cdot 3$ & $6.9 \dagger$ & $3 \cdot 7,10 \cdot 1$ \\
\hline $\begin{array}{l}\text { Energy intake (kJ) } \\
\text { Carbohydrates (\% El) }\end{array}$ & 8841 & 6355-10397 & 7799 & 6109-9389 & 9049 & $6125-11079$ & 7657 & $6029-8745$ & 8309 & $5908-9523$ & 6627 & 5418-8489 & $\begin{array}{l}0.96 \\
0.87\end{array}$ & $\begin{array}{r}-0.99 \\
1.31\end{array}$ & $\begin{array}{l}-0.79,1.25 \\
-5.8,8.4\end{array}$ & $\begin{array}{r}-0.98 \\
0.02\end{array}$ & $\begin{array}{l}-0.77,1.23 \\
-7 \cdot 1,7.1\end{array}$ \\
\hline $\begin{array}{l}\text { Mean } \\
\text { SD }\end{array}$ & & $\begin{array}{l}44.9 \\
10 \cdot 3\end{array}$ & & $\begin{array}{c}46 \cdot 2 \\
9 \cdot 8\end{array}$ & & $\begin{array}{c}44.6 \\
8.8\end{array}$ & & $\begin{array}{l}47 \cdot 4 \\
12 \cdot 1\end{array}$ & & $\begin{array}{c}47 \cdot 2 \\
8 \cdot 4\end{array}$ & & $\begin{array}{l}47.1 \\
6.7\end{array}$ & & & & & \\
\hline $\begin{array}{l}\text { Protein }(\% \mathrm{EI}) \\
\text { Mean } \\
\text { SD }\end{array}$ & & $\begin{array}{c}15.2 \\
3.2\end{array}$ & & $\begin{array}{c}16 \cdot 7 \\
2 \cdot 8\end{array}$ & & $\begin{array}{c}14 \cdot 7 \\
3.4\end{array}$ & & $\begin{array}{c}15 \cdot 3 \\
3.9\end{array}$ & & $\begin{array}{l}15 \cdot 6 \\
5 \cdot 6\end{array}$ & & $\begin{array}{l}17.1 \\
4.7\end{array}$ & 0.38 & $-1 \cdot 27$ & $-4 \cdot 1,1 \cdot 6$ & 0.29 & $-2 \cdot 6,3 \cdot 2$ \\
\hline $\begin{array}{l}\text { Fat }(\% \text { El) } \\
\text { Mean } \\
\text { SD }\end{array}$ & & $\begin{array}{c}40.5 \\
9.4\end{array}$ & & $\begin{array}{c}39.5 \\
8.5\end{array}$ & & $\begin{array}{c}42.4 \\
9.3\end{array}$ & & $\begin{array}{l}38 \cdot 3 \\
10 \cdot 9\end{array}$ & & $\begin{array}{c}38.2 \\
6.7\end{array}$ & & $\begin{array}{l}36.9 \\
5.2\end{array}$ & 0.71 & $-1 \cdot 6$ & $-8 \cdot 0,4 \cdot 8$ & $-2 \cdot 1$ & $-8 \cdot 4,4 \cdot 4$ \\
\hline $\begin{array}{l}\text { SFA (\% EI) } \\
\text { Mean } \\
\text { SD }\end{array}$ & & $\begin{array}{c}12.1 \\
3.4\end{array}$ & & $\begin{array}{c}12.1 \\
3.5\end{array}$ & & $\begin{array}{c}12 \cdot 2 \\
3.2\end{array}$ & & $\begin{array}{c}11 \cdot 6 \\
4.4\end{array}$ & & $\begin{array}{c}11.4 \\
3.2\end{array}$ & & $\begin{array}{l}10 \cdot 0 \\
3.0\end{array}$ & 0.18 & -0.45 & $-3 \cdot 3,2 \cdot 3$ & $-2 \cdot 0$ & $-4 \cdot 8,0 \cdot 8$ \\
\hline $\begin{array}{l}\text { MUFA (\% EI) } \\
\text { Mean } \\
\text { SD }\end{array}$ & & $\begin{array}{l}18 \cdot 8 \\
6 \cdot 4\end{array}$ & & $\begin{array}{l}17.1 \\
6 \cdot 06\end{array}$ & & $\begin{array}{l}19 \cdot 89 \\
8.2\end{array}$ & & $\begin{array}{l}22 \cdot 7 \\
9 \cdot 3\end{array}$ & & $\begin{array}{l}17.5 \\
4.2\end{array}$ & & $\begin{array}{l}8.03 \\
4.5\end{array}$ & $0.03 \dagger$ & $5.1 \dagger$ & $0.33,9.9$ & 1.5 & $-3 \cdot 2,6 \cdot 3$ \\
\hline $\begin{array}{l}\text { PUFA (\% EI) } \\
\text { Dietary fibre } \\
\text { (g/1000 kcal) }\end{array}$ & $\begin{array}{r}5 \cdot 3 \\
10 \cdot 5\end{array}$ & $\begin{array}{l}4 \cdot 0-6 \cdot 5 \\
7 \cdot 4-14 \cdot 6\end{array}$ & $\begin{array}{l}4.9 \\
7.5\end{array}$ & $\begin{array}{l}3 \cdot 8-6 \cdot 0 \\
4 \cdot 6-11 \cdot 5\end{array}$ & $\begin{array}{l}5 \cdot 1 \\
9 \cdot 0\end{array}$ & $\begin{array}{l}4.4-7.9 \\
6.8-11.5\end{array}$ & $\begin{array}{r}6 \cdot 0 \\
14 \cdot 6\end{array}$ & $\begin{array}{c}4 \cdot 9-8 \cdot 8 \\
11 \cdot 4-17\end{array}$ & $\begin{array}{r}105 \cdot 4 \\
9.3\end{array}$ & $\begin{array}{l}4 \cdot 4-6 \cdot 2 \\
4 \cdot 7-13 \cdot 7\end{array}$ & $\begin{array}{r}6 \cdot 0 \\
17 \cdot 0\end{array}$ & $\begin{array}{c}4 \cdot 5-6 \cdot 6 \\
13 \cdot 2-20 \cdot 1\end{array}$ & $\begin{array}{c}0.04 \dagger \\
<0.001 \dagger\end{array}$ & $\begin{array}{l}1.3 \dagger \\
1.96 \dagger\end{array}$ & $\begin{array}{l}1.01,1.69 \\
1.40,2.76\end{array}$ & $\begin{array}{l}1.2 \\
2 \cdot 24 \dagger\end{array}$ & $\begin{array}{r}-0.94,1.58 \\
1.59,3.15\end{array}$ \\
\hline $\begin{array}{l}\text { Sedentary activities (during } \\
\text { leisure time }(\mathrm{h} / \mathrm{d}) \text { ) }\end{array}$ & & & & & & & & & & & & & $0.02 \dagger$ & $-0.95 \dagger$ & $-1 \cdot 8,-0.05$ & $-0.90 \dagger$ & $-1 \cdot 8,-0.03$ \\
\hline $\begin{array}{l}\text { Mean } \\
\text { SD }\end{array}$ & & $\begin{array}{l}3.2 \\
1.9\end{array}$ & & $\begin{array}{l}3.6 \\
1.6\end{array}$ & & $\begin{array}{l}3.8 \\
1.5\end{array}$ & & $\begin{array}{l}3.0 \\
1.5\end{array}$ & & $\begin{array}{l}3 \cdot 7 \\
2 \cdot 1\end{array}$ & & $\begin{array}{l}3 \cdot 1 \\
1 \cdot 7\end{array}$ & & & & & \\
\hline $\begin{array}{l}\text { MET-min/d of low intensity } \\
\text { PA }\end{array}$ & 672 & $492-923$ & 603 & 464-906 & 705 & $606-901$ & 768 & 588-935 & 762 & $502-1032$ & 665 & 611-963 & 0.43 & 1.08 & $-0.85,1.37$ & -0.96 & $-0 \cdot 76,1 \cdot 21$ \\
\hline MET-min/d of moderate PA & 154 & $51-411$ & 153 & 28-316 & 180 & 49-387 & 205 & $103-429$ & 154 & $0-311$ & 171 & $17-447$ & 0.57 & -0.79 & $-0.23,2 \cdot 7$ & 1.36 & $-0.37,5.02$ \\
\hline $\begin{array}{l}\text { MET-min/d of vigorous PA } \\
\text { Total MET-min/d } \\
\text { PAL }\end{array}$ & $\begin{array}{r}0 \\
1623\end{array}$ & $\begin{array}{c}0-0 \\
1330-1875\end{array}$ & $\begin{array}{r}0 \\
1531\end{array}$ & $\begin{array}{c}0-0 \\
1365-1877\end{array}$ & $\begin{array}{r}0 \\
1718\end{array}$ & $\begin{array}{c}0-32 \\
1613-1810\end{array}$ & $\begin{array}{r}0 \\
1721\end{array}$ & $\begin{array}{c}0-51 \\
1489-1824\end{array}$ & $\begin{array}{r}0 \\
1655\end{array}$ & $\begin{array}{c}0-151 \\
1446-1880\end{array}$ & $\begin{array}{r}103 \\
1718\end{array}$ & $\begin{array}{c}0-238 \\
1613-1810\end{array}$ & $\begin{array}{l}<0.001 \dagger \\
0.10 \\
0.27\end{array}$ & $\begin{array}{l}1.36 \\
1.05 \\
0.03\end{array}$ & $\begin{array}{l}-0.37,5.02 \\
-0.95,1.15 \\
-0.080 .1\end{array}$ & $\begin{array}{r}14.5 \dagger \\
1.09 \\
0.07\end{array}$ & $\begin{array}{l}3.49,60.2 \\
-0.99,1.2 \\
-0.040 .2\end{array}$ \\
\hline $\begin{array}{l}\text { PAL } \\
\text { Mean } \\
\text { SD }\end{array}$ & & $\begin{array}{l}1.30 \\
0.14\end{array}$ & & $\begin{array}{l}1.29 \\
0.15\end{array}$ & & $\begin{array}{l}1.30 \\
0.16\end{array}$ & & $\begin{array}{l}1.34 \\
0.18\end{array}$ & & $\begin{array}{l}1.29 \\
0.20\end{array}$ & & $\begin{array}{l}1.37 \\
0.21\end{array}$ & & & $-0.08,0.1$ & & \\
\hline $\begin{array}{l}\text { Habitual sleep hours }(h / d) \\
\text { Mean } \\
\text { SD }\end{array}$ & & $\begin{array}{l}7.1 \\
1.25\end{array}$ & & $\begin{array}{l}7.1 \\
1.3\end{array}$ & & $\begin{array}{l}7.1 \\
1.3\end{array}$ & & $\begin{array}{c}6.9 \\
1\end{array}$ & & $\begin{array}{c}6.2 \\
1.30\end{array}$ & & $\begin{array}{l}6.8 \\
1.25\end{array}$ & 0.41 & -0.2 & $-0.9,0.4$ & 0.1 & $-0.5,0.8$ \\
\hline $\begin{array}{l}\text { Mid-day rest/naps (yes) } \neq \\
n \\
\%\end{array}$ & & $\begin{array}{c}8 \\
38.1\end{array}$ & & $\begin{array}{c}7 \\
33.3\end{array}$ & & $\begin{array}{c}11 \\
52 \cdot 4\end{array}$ & & $\begin{array}{c}10 \\
47.6\end{array}$ & & $\begin{array}{c}13 \\
61.9\end{array}$ & & $\begin{array}{c}15 \\
71 \cdot 4\end{array}$ & $0.04 \dagger$ & 0.65 & $0.16,2.5$ & $0.23 \dagger$ & $0.05,0.97$ \\
\hline $\begin{array}{l}\text { Optimal sleep duration } ¥ \S \\
n \\
\%\end{array}$ & & $\begin{array}{c}12 \\
57 \cdot 1\end{array}$ & & $\begin{array}{c}11 \\
52 \cdot 4\end{array}$ & & $\begin{array}{c}11 \\
52 \cdot 4\end{array}$ & & $\begin{array}{l}12 \\
57 \cdot 1\end{array}$ & & $\begin{array}{c}9 \\
42 \cdot 9\end{array}$ & & $\begin{array}{c}10 \\
47 \cdot 6\end{array}$ & 0.87 & 0.71 & $0 \cdot 2,2 \cdot 7$ & 0.95 & $0 \cdot 2,3 \cdot 6$ \\
\hline $\begin{array}{l}\text { Body weight }(\mathrm{kg}) \\
\% \text { Weight lossll } \\
\text { BMI }\left(\mathrm{kg} / \mathrm{m}^{2}\right)\end{array}$ & $\begin{array}{l}89 \cdot 3 \\
-2 \cdot 1 \\
30 \cdot 04\end{array}$ & $\begin{array}{c}79 \cdot 4-95 \cdot 2 \\
-3 \cdot 6,0 \cdot 3 \\
28 \cdot 2-33 \cdot 1\end{array}$ & $\begin{array}{l}86 \cdot 4 \\
29.49\end{array}$ & $\begin{array}{l}78 \cdot 4-95 \cdot 0 \\
27 \cdot 8-32 \cdot 9\end{array}$ & $\begin{array}{l}96 \cdot 7 \\
-5 \cdot 4 \\
31 \cdot 67\end{array}$ & $\begin{array}{l}79 \cdot 6-101 \\
-8 \cdot 2,-3 \cdot 3 \\
27 \cdot 4-33 \cdot 6\end{array}$ & $\begin{array}{l}83 \cdot 0 \\
28 \cdot 21\end{array}$ & $\begin{array}{l}75 \cdot 3-98 \cdot 0 \\
25 \cdot 9-31 \cdot 5\end{array}$ & $\begin{array}{l}96 \cdot 0 \\
-6 \cdot 3 \\
32 \cdot 44\end{array}$ & $\begin{array}{l}82 \cdot 0-104 \\
-8 \cdot 2,-1 \cdot 1 \\
28 \cdot 4-35 \cdot 0\end{array}$ & $\begin{array}{l}92.5 \\
30.55\end{array}$ & $\begin{array}{l}75 \cdot 5-101 \\
26 \cdot 6-33 \cdot 3\end{array}$ & $\begin{array}{l}0.14 \\
0.01 \dagger \\
0.008 \dagger\end{array}$ & $\begin{array}{l}-2 \cdot 7 \\
-2 \cdot 1 \dagger \\
-0.95 \dagger\end{array}$ & $\begin{array}{c}-6 \cdot 1,0.68 \\
-1 \cdot 1,-4 \cdot 1 \\
-0.92,-0.99\end{array}$ & $\begin{array}{l}-1.9 \\
-1.8 \dagger \\
-0.96 \dagger\end{array}$ & $\begin{array}{l}-5 \cdot 3,1.5 \\
-1.02,-3.5 \\
-0.93,1.00\end{array}$ \\
\hline 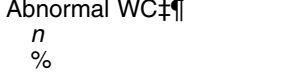 & & $\begin{array}{c}90.5 \\
19\end{array}$ & & $\begin{array}{c}76 \cdot 2 \\
16\end{array}$ & & $\begin{array}{c}76 \cdot 2 \\
16\end{array}$ & & $\begin{array}{c}47.6 \\
10\end{array}$ & & $\begin{array}{c}71.4 \\
15\end{array}$ & & $\begin{array}{l}61.9 \\
13\end{array}$ & 0.36 & 0.42 & $0 \cdot 07,2 \cdot 3$ & 0.29 & $0 \cdot 05,1 \cdot 8$ \\
\hline
\end{tabular}

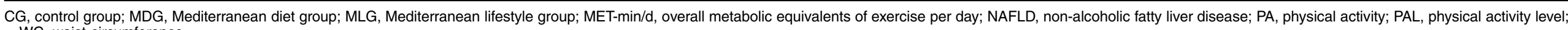

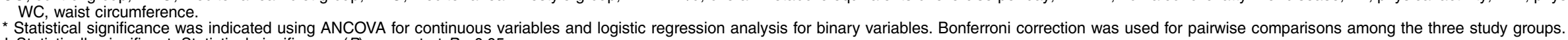
† Statistically significant. Statistical significance $(P)$ was set at $P<0.05$.

$\neq$ Adjusted differences for binary outcomes (i.e. mid-day rest/naps, optimal sleep duration, abnormal WC) are from logistic regression with the same fixed effects and covariates as the respective ANCOVA analyses. $\S$ Optimal sleep defined as sleep $\geq 7$ and $\leq 9 \mathrm{~h}$.

II Relative weight change

II WC $>102 \mathrm{~cm}$ for men and $>88 \mathrm{~cm}$ for women.

作

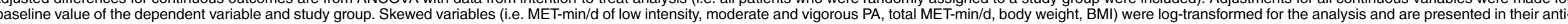
logarithm form. 
Table 3. Intervention effects on liver outcomes in the intention-to-treat population

(Medians and interquartile ranges (IQR, 25th-75th); mean values and standard deviations; adjusted differences and $95 \%$ confidence intervals; numbers and percentages)

\begin{tabular}{|c|c|c|c|c|c|c|c|c|c|c|c|c|c|c|c|c|c|}
\hline & \multicolumn{4}{|c|}{ CG $(n 21)$} & \multicolumn{4}{|c|}{ MDG $(n 21)$} & \multicolumn{4}{|c|}{ MLG $(n 21)$} & \multirow[b]{3}{*}{$P \dagger$} & \multirow{2}{*}{\multicolumn{2}{|c|}{ MDG $v . C G$}} & \multirow{2}{*}{\multicolumn{2}{|c|}{ MLG v. CG }} \\
\hline & \multicolumn{2}{|c|}{ Baseline } & \multicolumn{2}{|c|}{6 months } & \multicolumn{2}{|c|}{ Baseline } & \multicolumn{2}{|c|}{6 months } & \multicolumn{2}{|c|}{ Baseline } & \multicolumn{2}{|c|}{6 months } & & & & & \\
\hline & Median & IQR & Median & IQR & Median & IQR & Median & IQR & Median & IQR & Median & IQR & & $\begin{array}{l}\text { Adjusted } \\
\text { difference }^{\star}\end{array}$ & $95 \% \mathrm{Cl}$ & $\begin{array}{l}\text { Adjusted } \\
\text { difference }\end{array}$ & $95 \% \mathrm{Cl}$ \\
\hline ALT (U/I) & 44 & $24-64$ & 44 & $32-58$ & 51 & $30-73$ & 34 & $24-46$ & 54 & $39-81$ & 32 & $21-41$ & 0.09 & -0.79 & $-0.57,1.1$ & -0.75 & $-0.53,1.04$ \\
\hline ALT $<40 \mathrm{U} / \not$ & & & & & & & & & & & & & 0.08 & 0.62 & $0.15,2.5$ & $0.20 \S$ & $0.04,0.88$ \\
\hline $\begin{array}{l}n \\
\%\end{array}$ & \multicolumn{2}{|c|}{8} & \multicolumn{2}{|c|}{$\begin{array}{c}8 \\
38 \cdot 1\end{array}$} & \multicolumn{2}{|c|}{$\begin{array}{c}9 \\
42 \cdot 9\end{array}$} & \multicolumn{2}{|c|}{$\begin{array}{c}12 \\
57.1\end{array}$} & \multicolumn{2}{|c|}{$\begin{array}{c}5 \\
23 \cdot 8\end{array}$} & \multicolumn{2}{|c|}{15} & & & & & \\
\hline $\begin{array}{l}\text { ALT-50\% reduction } \neq \\
n \\
\%\end{array}$ & \multicolumn{4}{|c|}{$\begin{array}{c}2 \\
9.5\end{array}$} & \multicolumn{4}{|c|}{$\begin{array}{c}5 \\
23.8\end{array}$} & \multicolumn{4}{|c|}{$\begin{array}{c}11 \\
52 \cdot 4\end{array}$} & $0.009 \S$ & 0.33 & $0.05,2 \cdot 1$ & $0 \cdot 10 \S$ & $0.02,0.56$ \\
\hline $\begin{array}{l}\text { GGT }(U / I) \\
\text { GGT }<30 \mathrm{U} / \nsubseteq\end{array}$ & 64 & $34-170$ & 73 & $31-166$ & 65 & $28-96$ & 40 & $23-64$ & 71 & $37-178$ & 51 & $26-173$ & $\begin{array}{l}0.24 \\
0.36\end{array}$ & $\begin{array}{r}-0.79 \\
0.42\end{array}$ & $\begin{array}{l}-0.54,1.15 \\
0.07,2 \cdot 3\end{array}$ & $\begin{array}{r}-0.82 \\
0.32\end{array}$ & $\begin{array}{c}-0.57,1.17 \\
0.06,1.7\end{array}$ \\
\hline $\begin{array}{l}n \\
\%\end{array}$ & \multicolumn{2}{|r|}{2} & \multicolumn{2}{|r|}{3} & \multicolumn{3}{|c|}{5} & 3.3 & \multicolumn{2}{|c|}{1} & \multicolumn{2}{|c|}{6} & & & & & \\
\hline $\begin{array}{l}\text { Liver stiffness }(\mathrm{kPa}) \\
\text { Liver stiffness } \leq 6.6 \mathrm{kPa} \|\end{array}$ & $7 \cdot 8$ & $5.5-10.9$ & 8.0 & $6 \cdot 1-11 \cdot 1$ & $6 \cdot 6$ & $5 \cdot 5-9 \cdot 8$ & $6 \cdot 2$ & $5 \cdot 1-9 \cdot 9$ & $7 \cdot 1$ & $6 \cdot 3-8 \cdot 8$ & $6 \cdot 1$ & $5 \cdot 0-7 \cdot 6$ & $\begin{array}{l}0.002 \S \\
0.06\end{array}$ & $\begin{array}{l}-0.83 \S \\
0.09\end{array}$ & $\begin{array}{l}-0.70,-0.98 \\
0.08,1.1\end{array}$ & $\begin{array}{r}-0.78 \S \\
0.16 \S\end{array}$ & $\begin{array}{l}-0.66,-0.93 \\
0.03,0.9\end{array}$ \\
\hline $\begin{array}{l}n \\
\%\end{array}$ & \multicolumn{2}{|c|}{7} & & $\begin{array}{l}6 \\
8 \cdot 6\end{array}$ & $\begin{array}{r}1 \\
52\end{array}$ & $\begin{array}{l}1 \\
2.4\end{array}$ & $\begin{array}{r}1 \\
55\end{array}$ & $\begin{array}{l}2 \\
5.0\end{array}$ & & $\begin{array}{l}7 \\
3 \cdot 3\end{array}$ & & $\begin{array}{l}2 \\
7 \cdot 1\end{array}$ & & & & & \\
\hline $\begin{array}{l}\text { NAFLD fibrosis score } \\
\text { Mean } \\
\text { SD }\end{array}$ & & $\begin{array}{l}2.19 \\
1.4\end{array}$ & & $\begin{array}{l}2.21 \\
1 \cdot 1\end{array}$ & $\begin{array}{r}-2 \\
1\end{array}$ & 36 & $\begin{array}{r}-2 \\
1\end{array}$ & 38 & & $\begin{array}{l}2.11 \\
.3\end{array}$ & & .09 & 0.65 & -0.15 & $-0 \cdot 70,0 \cdot 40$ & -0.20 & $-0.74,0.34$ \\
\hline
\end{tabular}

CG, control group; MDG, Mediterranean diet group; MLG, Mediterranean lifestyle group; ALT, alanine transaminase; AST, aspartate transaminase; GGT, $\gamma$-glutamyl-transpeptidase; NAFLD fibrosis score, index range: >0.676 - presence of fibrosis, <1.455 - absence of fibrosis, 1.455 to 0.675: indeterminate score.

* Adjusted differences for continuous outcomes are from ANCOVA with data from intention-to-treat analysis (i.e. all patients who were randomly assigned to a study group were included). Adjustments were made for baseline value of the dependent variable, \% weight loss and study group. Skewed variables (i.e. ALT, GGT and liver stiffness) were log-transformed for the analysis and are presented in their anti-logarithm form.

Stalistical significance was indicated using ANCOVA for continuous variables and logistic regression analysis for binary variables. Bonferroni correction was used for pairwise comparisons among the three study groups.

‡ Adjusted differences for binary outcomes (i.e. ALT $<40 \mathrm{U} / \mathrm{l}$, ALT-50\% reduction, GGT $<30 \mathrm{U} / \mathrm{l}$ and liver stiffness $<6.6 \mathrm{kPa}$ ) are from logistic regression with the same fixed effects and covariates as the respective ANCOVA analyses.

\|I As reviewed by Abenavoli et al. ${ }^{(32)}$ values of liver stiffness $>6.6$ or $\leq 6.6 \mathrm{kPa}$ suggests the presence of significant or not fibrosis, respectively. 
Table 4. Intervention effects on biochemical profile in the intention-to-treat population

(Medians and interquartile ranges (IQR, 25th-75th); mean values and standard deviations; adjusted differences and $95 \%$ confidence intervals)

\begin{tabular}{|c|c|c|c|c|c|c|c|c|c|c|c|c|c|c|c|c|c|}
\hline & \multicolumn{4}{|c|}{ CG $(n 21)$} & \multicolumn{4}{|c|}{ MDG $(n 21)$} & \multicolumn{4}{|c|}{ MLG $(n 21)$} & \multirow[b]{3}{*}{$P \dagger$} & \multirow{2}{*}{\multicolumn{2}{|c|}{ MDG $v . C G$}} & \multirow{2}{*}{\multicolumn{2}{|c|}{ MLG $v . C G$}} \\
\hline & \multicolumn{2}{|c|}{ Baseline } & \multicolumn{2}{|c|}{6 months } & \multicolumn{2}{|c|}{ Baseline } & \multicolumn{2}{|c|}{6 months } & \multicolumn{2}{|c|}{ Baseline } & \multicolumn{2}{|c|}{6 months } & & & & & \\
\hline & Median & IQR & Median & IQR & Median & IQR & Median & IQR & Median & IQR & Median & IQR & & $\begin{array}{c}\text { Adjusted } \\
\text { difference } \neq\end{array}$ & $95 \% \mathrm{Cl}$ & $\begin{array}{c}\text { Adjusted } \\
\text { difference } \neq\end{array}$ & $95 \% \mathrm{Cl}$ \\
\hline Glucose $(\mathrm{mmol} / \mathrm{l})$ & \multirow{2}{*}{\multicolumn{2}{|c|}{$5 \cdot 0$}} & \multicolumn{2}{|c|}{$5 \cdot 1$} & \multicolumn{2}{|r|}{$5 \cdot 1$} & \multirow{2}{*}{\multicolumn{2}{|c|}{5.1}} & \multirow{2}{*}{\multicolumn{2}{|c|}{4.9}} & \multirow{2}{*}{\multicolumn{2}{|c|}{4.8}} & 0.75 & -0.7 & $-7 \cdot 2,5 \cdot 7$ & -1.9 & $-8 \cdot 2,4 \cdot 3$ \\
\hline $\begin{array}{l}\text { Mean } \\
\text { SD }\end{array}$ & & & \multicolumn{2}{|c|}{0.46} & \multicolumn{2}{|c|}{$\begin{array}{c}5.1 \\
0.63\end{array}$} & & & & & & & & & & & \\
\hline Insulin (pmol/l) & $85 \cdot 4$ & $57 \cdot 4-122 \cdot 0$ & 78.9 & $48 \cdot 1-121 \cdot 3$ & $116 \cdot 2$ & $71 \cdot 7-147 \cdot 8$ & 85.4 & $61 \cdot 0-127.0$ & $100 \cdot 4$ & $64 \cdot 6-147 \cdot 1$ & $86 \cdot 1$ & $53 \cdot 1-122 \cdot 0$ & 0.78 & $-1 \cdot 0$ & $-0.7,1.4$ & -0.9 & $-0.7,1.3$ \\
\hline HOMA-IR & $2 \cdot 5$ & $1 \cdot 7-4 \cdot 0$ & 2.5 & $1 \cdot 4-3 \cdot 6$ & 3.4 & $1 \cdot 9-5 \cdot 1$ & $2 \cdot 6$ & $1 \cdot 7-4 \cdot 1$ & $3 \cdot 3$ & $2 \cdot 0-5 \cdot 0$ & $2 \cdot 7$ & $1 \cdot 4-3 \cdot 8$ & 0.60 & $-1 \cdot 1$ & $-0.74,1.5$ & -0.9 & $-0.6,1 \cdot 3$ \\
\hline TC (mmol/l) & \multirow{2}{*}{\multicolumn{2}{|c|}{$5 \cdot 3$}} & \multirow{2}{*}{\multicolumn{2}{|c|}{$5 \cdot 6$}} & \multirow{3}{*}{\multicolumn{2}{|c|}{$5 \cdot 1$}} & \multirow{3}{*}{\multicolumn{2}{|c|}{$4 \cdot 8$}} & \multirow{3}{*}{\multicolumn{2}{|c|}{$5 \cdot 2$}} & & & 0.08 & -0.9 & $-0.7,1 \cdot 0$ & -0.9 & $-0.8,1 \cdot 1$ \\
\hline Mean & & & & & & & & & & & \multirow{2}{*}{\multicolumn{2}{|c|}{$5 \cdot 2$}} & & & & & \\
\hline SD & \multirow{2}{*}{\multicolumn{2}{|c|}{$1 \cdot 0$}} & & $1 \cdot 2$ & & & & & & & & & & & & & \\
\hline TAG $(\mathrm{mmol} / \mathrm{l})$ & & & & & & & & & & & & & 0.28 & -0.8 & $-0.7,1 \cdot 1$ & -0.9 & $-0.7,1.1$ \\
\hline Mean & & 1.5 & & 1.5 & & 1.5 & & 1.2 & & 1.8 & & 1.5 & & & & & \\
\hline $\mathrm{SD}$ & & 0.78 & & 0.74 & & 1.02 & & 0.57 & & 0.94 & & 0.65 & & & & & \\
\hline $\mathrm{HDL}(\mathrm{mmol} / \mathrm{l})$ & $1 \cdot 1$ & $0.9-1.5$ & $1 \cdot 1$ & $0.9-1.6$ & 1.0 & $0.9-1.5$ & $1 \cdot 1$ & $1.0-1 \cdot 6$ & $1 \cdot 1$ & $0.9-1.3$ & $1 \cdot 1$ & $0.9-1.3$ & $0.04 \ddagger$ & $+1 \cdot 1$ & $-0 \cdot 9,1 \cdot 2$ & -0.9 & $-0.9,1 \cdot 1$ \\
\hline LDL (mmol/l') & & & & & & & & & & & & & $0.04 \ddagger$ & $-0.8 \ddagger$ & $-0.7,-0.9$ & -0.9 & $-0.8,1 \cdot 1$ \\
\hline Mean & & $3 \cdot 3$ & & 3.6 & & $3 \cdot 2$ & & $2 \cdot 9$ & & $3 \cdot 1$ & & $3 \cdot 2$ & & & & & \\
\hline SD & & 0.9 & & 1.0 & & 1.0 & & 0.9 & & 0.8 & & 1.0 & & & & & \\
\hline Non-HDL $(\mathrm{mmol} / \mathrm{l}) \S$ & 3.9 & $3 \cdot 3-4 \cdot 8$ & $4 \cdot 2$ & $3 \cdot 2-5 \cdot 4$ & 3.7 & $3 \cdot 1-4 \cdot 7$ & 3.5 & $2 \cdot 6-4 \cdot 2$ & 4.1 & $3 \cdot 3-4.5$ & 3.9 & $3 \cdot 2-5 \cdot 1$ & $0.04 \ddagger$ & $-1.5 \ddagger$ & $-2 \cdot 2,-1 \cdot 0$ & $-1 \cdot 2$ & $-1 \cdot 7,1 \cdot 2$ \\
\hline TAG:HDL ratio & $2 \cdot 1$ & $1.4-4.9$ & $2 \cdot 2$ & $1.4-4.7$ & 2.4 & $1.3-4.4$ & 1.8 & $1.3-4.9$ & 3.9 & $1.5-4.6$ & $3 \cdot 3$ & $1.2-4.7$ & 0.16 & -1.64 & $-3 \cdot 1,1 \cdot 1$ & -1.32 & $-2 \cdot 4,1.4$ \\
\hline
\end{tabular}

CG, control group; MDG, Mediterranean diet group; MLG, Mediterranean lifestyle group; HOMA-IR, homoeostasis model assessment of insulin resistance; TC, total cholesterol.

* Statistical significance was indicated using ANCOVA. Bonferroni correction was used for pairwise comparisons among the three study groups.

† Statistically significant. Statistical significance $(P)$ was set at $P<0.05$.

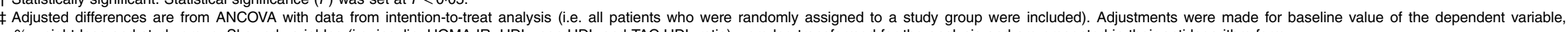

$\%$ weight loss and study group. Skewed variables (i.e. insulin, HOMA-IR, HDL, non-HDL and TAG:HDL ratio) were log-transformed for the analysis and are presented in their anti-logarithm form.

$\S$ Non-HDL: determined by TC minus HDL-cholesterol. 
approaches, encourage patients to initiate and adhere to lifestyle modifications, aiming at weight loss, engagement in physical activities and adoption of healthy dietary habits, as keystones in NAFLD management ${ }^{(1,35)}$. Weight loss has been suggested as the most important factor for NAFLD treatment ${ }^{(36)}$, and most of the studies providing hypoenergetic feeding regimes (alone or in combination with physical activity) in NAFLD patients have shown significant improvements in both liver enzymes and liver fat content ${ }^{(37,38)}$. Indeed, according to the American Association for the Study of Liver Diseases, 3-5\% of weight loss is necessary to improve liver steatosis ${ }^{(39)}$, although a greater weight loss (up to $10 \%$ ) may be required for histological improvements and NAFLD resolution ${ }^{(39,40,41)}$. Furthermore, there are data supporting that as long as energetic restriction is applied the macronutrient composition of the diet (namely low-fat or low-carbohydrate diets) has little impact on NAFLD management ${ }^{(35)}$. In our protocol, we aimed at a small weight loss (approximately 5\%) in all study groups, although only the intensive intervention groups achieved this weight loss. Furthermore, even though the diets that participants complied with had similar macronutrient composition in all study groups, different effects on biochemical and clinical liver function outcomes were recorded, after controlling for weight loss, implying that other characteristics of the intensive interventions (e.g. the Mediterranean dietary pattern or the physical activity) could have contributed to these outcomes.

Regarding interventions based on the Mediterranean pattern, so far there are three published clinical trials ${ }^{(16,17,42)}$ exploring the effect of a MD-based intervention on NAFLD; however, owing to methodological limitations, only the Australian randomised cross-over clinical trial by Ryan et al. ${ }^{(17)}$ supports clear benefits of the adherence to the MD. In this study, 12 volunteers with NAFLD were assigned either to MD or lowfat high-carbohydrate diet (control diet) for a 6-week period. Rapid hepatic steatosis improvements, as measured by ${ }^{1} \mathrm{H}-\mathrm{MRS}$, and increases in insulin sensitivity, as measured by hyperinsulinaemic-euglycaemic clamp, were observed only in the MD compared with the CG. Moreover, in this study, a minimal and not significant weight loss was recorded that did not differ between the two study groups. In our study, the MDG, which received an intervention aiming only at increasing adherence to the MD, although achieving a weight reduction similar to that of the MLG, showed improvements only in liver stiffness compared with the CG, after controlling for weight loss, and not in liver enzyme levels.

MD has been suggested to exhibit beneficial effects in NAFLD treatment mainly owing to its foods choices with predominantly anti-inflammatory and antioxidant properties ${ }^{(43-45)}$. Indeed, both the intensive care groups showed a significant increase in the consumption of whole grains, fruit, vegetables and nuts. Several phytochemicals and vitamins, from fruits and vegetables, and the low glycaemic response owing to the high content of fibres, appear to be some of the mechanisms through which the MD might lower the degree of hepatic steatosis in NAFLD patients ${ }^{(43)}$. Moreover, reductions in refined cereals, potatoes and red meat consumption that have been also observed in our study have been suggested to benefit NAFLD patients $^{(46)}$, as these food groups have been constantly associated with higher insulin resistance in apparently healthy populations $^{(47,48)}$, as well as in NAFLD patients ${ }^{(49)}$.

Apart from changes in the MD, both the intensive groups decreased time spent in sedentary activities, whereas MLG further increased vigorous exercise. Several studies support beneficial effects of physical exercise interventions on NAFLD in terms of improving intrahepatic lipid content and aminotransferase blood levels ${ }^{(8)}$. Indeed, these effects have been recorded irrespectively of the presence of obesity ${ }^{(50)}$ and weight reduction ${ }^{(7)}$. Moreover, reductions in sitting time have a positive effect on insulin resistance in patients with NAFLD ${ }^{(51)}$, whereas long-term physical activity can lead to significant increase in the circulating soluble receptor of advanced glycation end (AGE) products levels, a sign of decreased AGE-mediated inflammation, which has been linked with NAFLD presence ${ }^{(52)}$ and progression ${ }^{(53)}$. As far as sleep habits are concerned, mid-day rest/naps differed significantly in the MLG compared with the CG, whereas during the intervention participants in the MLG also increased the initially reduced sleep hours. The effect of sleep habits on NAFLD has not been thoroughly studied. Short sleep duration $(\leq 5 v .>7 \mathrm{~h})$ and poor sleep quality have been associated with an increased risk of NAFLD in men ${ }^{(54)}$. In addition, a 'healthy diet-optimal sleep lifestyle pattern' has been inversely associated with liver stiffness and insulin resistance, independently of BMI and energy intake in a sample of NAFLD patients ${ }^{(49)}$. Whether changes in sleep habits have partially contributed to the liver benefits observed in the MLG is hard to tell given the small changes achieved by the participants. Nevertheless, the MLG improved most of the liver parameters examined (i.e. ALT normalisation, ALT reduction to half levels, liver stiffness) compared with the CG, even after weight loss was taken into account. This fact suggests a potential synergistic and cumulative effect of the combination of adherence to the MD with enhanced physical activity and improved sleep habits, compared with the MD alone in NAFLD management. This intercorrelation of lifestyle habits has been also highlighted in the more recent description of the $\mathrm{MD}^{(18)}$, in which MD is described as a lifestyle and not just a dietary pattern, attributing part of its properties in physical activity, adequate night sleep and mid-day rest ${ }^{(18)}$. This perspective has been also discussed by Ancel Keys and the other researchers who participated in the Seven countries study ${ }^{(55)}$, and is also acknowledged by UNESCO, which inscribed MedDiet on the Representative List of the Intangible Cultural Heritage of Humanity and describes it as 'a way of life - a lifestyle'.

Regarding pathophysiological pathways, insulin resistance is considered the key pathogenic factor for NAFLD development and progression ${ }^{(56)}$. However, in the present study, HOMA-IR, as a measure of insulin resistance, did not differ between groups at the end of the study. Possibly, other markers, more sensitive to changes in insulin resistance and insulin sensitivity, such as the use of hyperglycaemic clamp or hyperinsulinaemiceuglycaemic clamp methods, could have better identified potential changes in insulin resistance ${ }^{(57,58)}$. Nevertheless, according to the 'multiple hit' hypothesis, NAFLD pathogenesis is multifactorial ${ }^{(5)}$. Thus, we cannot rule out the possibility that alterations in other pathophysiological factors such as in 
proinflammatory cytokines production, adipokines, markers of oxidative stress or intestinal microbiome permeability might have mediated the beneficial effects of the Mediterranean lifestyle on NAFLD liver function outcomes.

NFS and liver stiffness determined by elastography are considered as useful non-invasive tools for the assessment of the severity of hepatic fibrosis in NAFLD patients, whereas elastrography has been reported to have better diagnostic performance for such assessment compared with $\mathrm{NFS}^{(59,60)}$. However, their changes after any intervention and particularly the kinetics of these changes are not well studied. In the present study, liver stiffness improved in both intensive intervention groups, whereas NFS remained unchanged. A possible explanation might be that multiple processes, other than fibrosis, can contribute to elastographic liver stiffness, that is inflammation and fat content ${ }^{(61,62)}$, which could improve much earlier than fibrosis itself after intervention leading to improved LSM without improvement in fibrosis.

The present study is not deprived of limitations. One limitation is the high dropout rate that was recorded in the CG. Given the higher severity of their condition (i.e. higher liver stiffness and BMI compared with the controls who did not drop out), probably these patients were looking for a closer monitoring of their diet. Nevertheless, the analysis was performed in the ITT population (i.e. including all patients who were randomly allocated to a study group), and without significant differences compared with the sensitivity (i.e. per protocol) analyses. Diagnosis of the disease was based on evidence of hepatic steatosis on ultrasound combined with elevated ALT and/or GGT levels. The upper limit of normal ALT used in current study was the traditional one (i.e. ALT $<40 \mathrm{U} / \mathrm{I}$ ) and not the lower limits suggested by Prati et $a{ }^{(63)}$ that have not been validated in our population. Nevertheless, the efficacy of our intervention was based not only on the clinically significant decreases of ALT within normal levels but also to the $50 \%$ decrease of its initial levels. In addition, NAFLD severity assessment was based on shear-wave elastography instead of liver biopsy, which is the gold-standard method. However, as liver biopsy is an invasive procedure carrying potential risks of several complications, newer commercially available devices of liver elastography, such as share-wave elastography, provide improved diagnostic accuracy compared with other elastographic methods and limit various physical limitations of the method, including the presence of obesity. On the other hand, the proposed intervention is simple and does not require sophisticated equipment, making intervention feasible even in healthcare services of limited resources, whereas it is based on small changes in everyday life that could constitute a realistic plan for the majority of NAFLD patients.

\section{Conclusions}

Compared with usual clinical care, a 6-month weight-loss programme based on Mediterranean lifestyle was successful in improving liver function outcomes, namely ALT levels and liver stiffness in NAFLD patients, after adjusting for weight loss. Therefore, small changes in everyday life towards the
Mediterranean lifestyle, along with weight loss, can be a successful treatment option for patients with NAFLD.

\section{Acknowledgements}

The authors would like to thank all the participants who took part in the study and all the colleagues from Harokopio University, Laiko and Hippokration General Hospital who contributed their expertise to this study.

C. N. K. has received a Fellowship of Excellence for Postgraduate Research in Greece-Siemens Program, awarded by the State Scholarships Foundation (IKY). However, the State Scholarships Foundation had no role in the design, analysis or writing of this article. This research received no specific grant from any funding agency, commercial or not-for-profit sectors.

G. V. P. and M. D. K. contributed to the study concept and design; C. N. K., G. V. P., P. I., M. D., A. A., N. P. and M.-V. P. contributed to the acquisition of the data; C. N. K. and E. F. conducted the biochemical analysis; C. N. K. performed the statistical analyses and drafted the manuscript; G. V. P., E. F. and M. D. K. critically revised the manuscript and all authors read and approved the final manuscript.

The authors declare that there are no conflicts of interest.

\section{Supplementary material}

For supplementary material/s referred to in this article, please visit https://doi.org/10.1017/S000711451800137X

\section{References}

1. European Association for the Study of the Liver (EASL), European Association for the Study of Diabetes (EASD) \& European Association for the Study of Obesity (EASO) (2016) Clinical Practice Guidelines for the management of non-alcoholic fatty liver disease. J Hepatol 64, 1388-1402.

2. Ballestri S, Zona S, Targher G, et al. (2016) Nonalcoholic fatty liver disease is associated with an almost twofold increased risk of incident type 2 diabetes and metabolic syndrome. Evidence from a systematic review and meta-analysis. J Gastroenterol Hepatol 31, 936-944.

3. Miele L \& Targher G (2015) Understanding the association between developing a fatty liver and subsequent cardiometabolic complications. Expert Rev Gastroenterol Hepatol 9 , $1243-1245$.

4. Levene AP \& Goldin RD (2012) The epidemiology, pathogenesis and histopathology of fatty liver disease. Histopathology 61, 141-152.

5. Buzzetti E, Pinzani M \& Tsochatzis EA (2016) The multiple-hit pathogenesis of non-alcoholic fatty liver disease (NAFLD). Metabolism 65, 1038-1048.

6. Rinella ME, Loomba R, Caldwell SH, et al. (2014) Controversies in the diagnosis and management of NAFLD and NASH. Gastroenterol Hepatol (N Y) 10, 219-227.

7. Katsagoni $\mathrm{CN}$, Georgoulis $\mathrm{M}$, Papatheodoridis $\mathrm{GV}$, et al. (2017) Effects of lifestyle interventions on clinical characteristics of patients with non-alcoholic fatty liver disease: a metaanalysis. Metabolism 68, 119-132.

8. Orci LA, Gariani K, Oldani G, et al. (2016) Exercise-based interventions for nonalcoholic fatty liver disease: a meta-analysis 
and meta-regression. Clin Gastroenterol Hepatol $\mathbf{1 4}$ 1398-1411.

9. Keating SE, Hackett DA, George J, et al. (2012) Exercise and non-alcoholic fatty liver disease: a systematic review and meta-analysis. J Hepatol 57, 157-166.

10. Musso G, Cassader M, Rosina F, et al. (2012) Impact of current treatments on liver disease, glucose metabolism and cardiovascular risk in non-alcoholic fatty liver disease (NAFLD): a systematic review and meta-analysis of randomised trials. Diabetologia 55, 885-904.

11. Sofi F, Macchi C, Abbate R, et al. (2014) Mediterranean diet and health status: an updated meta-analysis and a proposal for a literature-based adherence score. Public Health Nutr 17, 2769-2782.

12. Esposito K, Maiorino MI, Bellastella G, et al. (2017) Mediterranean diet for type 2 diabetes: cardiometabolic benefits. Endocrine 56, 27-32.

13. Grosso G, Marventano S, Yang J, et al. (2017) A comprehensive meta-analysis on evidence of Mediterranean diet and cardiovascular disease: are individual components equal? Crit Rev Food Sci Nutr 57, 3218-3232.

14. Kontogianni MD, Tileli N, Margariti A, et al. (2014) Adherence to the Mediterranean diet is associated with the severity of non-alcoholic fatty liver disease. Clin Nutr 33, 678-683.

15. Georgoulis M, Kontogianni MD, Margariti A, et al. (2015) Associations between dietary intake and the presence of the metabolic syndrome in patients with non-alcoholic fatty liver disease. J Hum Nutr Diet 28, 409-415.

16. Trovato FM, Catalano D, Martines GF, et al. (2015) Mediterranean diet and non-alcoholic fatty liver disease: the need of extended and comprehensive interventions. Clin Nutr 34, 86-88.

17. Ryan MC, Itsiopoulos C, Thodis T, et al. (2013) The Mediterranean diet improves hepatic steatosis and insulin sensitivity in individuals with non-alcoholic fatty liver disease. J Hepatol 59, 138-143.

18. Bach-Faig A, Berry EM, Lairon D, et al. (2011) Mediterranean diet pyramid today. Science and cultural updates. Public Health Nutr 14, 2274-2284.

19. Moher D, Hopewell S, Schulz KF, et al. (2010) CONSORT 2010 explanation and elaboration: updated guidelines for reporting parallel group randomised trials. J Clin Epidemiol 63, e1-e37.

20. Cullen KWB, Baranowski T \& Smith SP (2001) Using goal setting as a strategy for dietary behavior change. J Am Diet Assoc 101, 562-566.

21. Ministry of Health \& Welfare of Greece (1999) Dietary guidelines for adults in Greece. Arch Hellenic Med 16, 516-524.

22. Mukherjee S, Patel SR, Kales SN, et al. (2015) An official American Thoracic Society statement: the importance of healthy sleep. Recommendations and future priorities. $A m \mathrm{~J}$ Respir Crit Care Med 191, 1450-1458.

23. Bountziouka V, Bathrellou E, Giotopoulou A, et al. (2012) Development, repeatability and validity regarding energy and macronutrient intake of a semi-quantitative food frequency questionnaire: methodological considerations. Nutr Metab Cardiovasc Dis 22, 659-667.

24. Panagiotakos DB, Pitsavos C, Arvaniti F, et al. (2007) Adherence to the Mediterranean food pattern predicts the prevalence of hypertension, hypercholesterolemia, diabetes and obesity, among healthy adults; the accuracy of the MedDietScore. Prev Med 44, 335-340.

25. Moshfegh AJ, Friday JE, Goldman JP, et al. (1999) Presence of inulin and oligofructose in the diets of Americans. J Nutr 129, 1407S-1411S

26. Kavouras SA, Maraki MI, Kollia M, et al. (2016) Development, reliability and validity of a physical activity questionnaire for estimating energy expenditure in Greek adults. Sci Sports $\mathbf{3 1}$, e47-e53.

27. Sedentary Behaviour Research Network (2012) Letter to the editor: standardized use of the terms 'sedentary' and 'sedentary behaviours'. Appl Physiol Nutr Metab 37, 540-542.

28. Soldatos CR, Dikeos DG \& Paparrigopoulos TJ (2003) The diagnostic validity of the Athens Insomnia Scale. J Psychosom Res 55, 263-267.

29. Friedewald WT, Levy RI \& Fredrickson DS (1972) Estimation of the concentration of low-density lipoprotein cholesterol in plasma, without use of the preparative ultracentrifuge. Clin Chem 18, 499-502.

30. Matthews DR, Hosker JP, Rudenski AS, et al. (1985) Homeostasis model assessment: insulin resistance and beta-cell function from fasting plasma glucose and insulin concentrations in man. Diabetologia 28, 412-419.

31. Angulo P, Hui JM, Marchesini G, et al. (2007) The NAFLD fibrosis score: a noninvasive system that identifies liver fibrosis in patients with NAFLD. Hepatology 45, 846-854.

32. Abenavoli L \& Beaugrand M (2012) Transient elastography in non-alcoholic fatty liver disease. Ann Hepatol 11, $172-178$.

33. Georgoulis M, Kontogianni MD, Tileli N, et al. (2014) The impact of cereal grain consumption on the development and severity of non-alcoholic fatty liver disease. Eur J Nutr $\mathbf{5 3}$, $1727-1735$

34. Liao JM \& Stack CB (2017) Annals understanding clinical research: implications of missing data due to dropout. Ann Intern Med 166, 596-598.

35. Marchesini G, Petta S \& Dalle Grave R (2016) Diet, weight loss, and liver health in nonalcoholic fatty liver disease: Pathophysiology, evidence, and practice. Hepatology 63, 2032-2043.

36. Romero-Gomez M, Zelber-Sagi S \& Trenell M (2017) Treatment of NAFLD with diet, physical activity and exercise. J Hepatol 67, 829-846.

37. Parry SA \& Hodson L (2017) Influence of dietary macronutrients on liver fat accumulation and metabolism. J Investig Med 65, 1102-1115.

38. McCarthy EM \& Rinella ME (2012) The role of diet and nutrient composition in nonalcoholic Fatty liver disease. J Acad Nutr Diet 112, 401-409.

39. Chalasani N, Younossi Z, Lavine JE, et al. (2012) The diagnosis and management of non-alcoholic fatty liver disease: practice guideline by the American Association for the Study of Liver Diseases, American College of Gastroenterology, and the American Gastroenterological Association. Am J Gastroenterol 107, 811-826.

40. Vilar-Gomez E, Martinez-Perez Y, Calzadilla-Bertot L, et al. (2015) Weight loss through lifestyle modification significantly reduces features of nonalcoholic steatohepatitis. Gastroenterology 149, 367-378, e365; quiz e314-365.

41. Wong VW, Chan RS, Wong GL, et al. (2013) Community-based lifestyle modification programme for non-alcoholic fatty liver disease: a randomized controlled trial. $J$ Hepatol 59 , 536-542.

42. Misciagna G, Del Pilar Diaz M, Caramia DV, et al. (2017) Effect of a low glycemic index Mediterranean diet on non-alcoholic fatty liver disease. A randomized controlled clinici trial. J Nutr Health Aging 21, 404-412.

43. Godos J, Federico A, Dallio M, et al. (2017) Mediterranean diet and nonalcoholic fatty liver disease: molecular mechanisms of protection. Int J Food Sci Nutr 68, 18-27.

44. Abenavoli L, Greco M, Milic N, et al. (2017) Effect of Mediterranean diet and antioxidant formulation in non-alcoholic fatty liver disease: a randomized study. Nutrients $\mathbf{9}, 870$. 
45. Zelber-Sagi S, Salomone F \& Mlynarsky L (2017) The Mediterranean dietary pattern as the diet of choice for nonalcoholic fatty liver disease: evidence and plausible mechanisms. Liver Int 37, 936-949.

46. Finelli C \& Tarantino G (2012) Is there any consensus as to what diet or lifestyle approach is the right one for NAFLD patients? J Gastrointestin Liver Dis 21, 293-302.

47. Kim Y, Keogh JB \& Clifton PM (2017) Consumption of red and processed meat and refined grains for 4 weeks decreases insulin sensitivity in insulin-resistant adults: a randomized crossover study. Metabolism 68, 173-183.

48. Kim Y, Keogh JB \& Clifton PM (2016) Differential effects of red meat/refined grain diet and dairy/chicken/nuts/whole grain diet on glucose, insulin and triglyceride in a randomized crossover study. Nutrients $\mathbf{8}, 687$.

49. Katsagoni CN, Papatheodoridis GV, Papageorgiou MV, et al. (2017) A 'healthy diet-optimal sleep' lifestyle pattern is inversely associated with liver stiffness and insulin resistance in patients with nonalcoholic fatty liver disease. Appl Physiol Nutr Metab 42, 250-256.

50. Bae JC, Suh S, Park SE, et al. (2012) Regular exercise is associated with a reduction in the risk of NAFLD and decreased liver enzymes in individuals with NAFLD independent of obesity in Korean adults. PLOS ONE 7, e46819.

51. Sabinicz A, Maciejewska D, Kaczorowska M, et al. (2016) Reduction of sitting time has a positive effect on the decrease of insulin resistance in patients with non-alcoholic fatty liver disease. Prz Gastroenterol 11, 257-262.

52. Palma-Duran SA, Kontogianni MD, Vlassopoulos A, et al. (2018) Serum levels of advanced glycation end-products (AGEs) and the decoy soluble receptor for AGEs (sRAGE) can discriminate non-alcoholic fatty liver disease in age-, sex- and BMI-matched normo-glycemic adults. Metabolism 83, $120-127$.

53. Sponder M, Campean IA, Emich M, et al. (2018) Long-term physical activity leads to a significant increase in serum sRAGE levels: a sign of decreased AGE-mediated inflammation due to physical activity? Heart Vessels (epublication ahead of print version 24 January 2018).

54. Kim CW, Yun KE, Jung HS, et al. (2013) Sleep duration and quality in relation to non-alcoholic fatty liver disease in middle-aged workers and their spouses. J Hepatol 59, 351-357.

55. Keys A (1986) Serum cholesterol response to dietary cholesterol. Am J Clin Nutr 44, 309

56. Bugianesi E, Moscatiello S, Ciaravella MF, et al. (2010) Insulin resistance in nonalcoholic fatty liver disease. Curr Pharm Des 16. 1941-1951.

57. Tam CS, Xie W, Johnson WD, et al. (2012) Defining insulin resistance from hyperinsulinemic-euglycemic clamps. Diabetes Care 35, 1605-1610.

58. Singh B \& Saxena A (2010) Surrogate markers of insulin resistance: a review. World J Diabetes 1, 36-47.

59. Aykut UE, Akyuz U, Yesil A, et al. (2014) A comparison of FibroMeter NAFLD Score, NAFLD fibrosis score, and transient elastography as noninvasive diagnostic tools for hepatic fibrosis in patients with biopsy-proven non-alcoholic fatty liver disease. Scand J Gastroenterol 49, 1343-1348.

60. Xiao G, Zhu S, Xiao X, et al. (2017) Comparison of laboratory tests, ultrasound, or magnetic resonance elastography to detect fibrosis in patients with nonalcoholic fatty liver disease: a meta-analysis. Hepatology 66, 1486-1501.

61. Karanjia RN, Crossey MM, Cox IJ, et al. (2016) Hepatic steatosis and fibrosis: non-invasive assessment. World $J$ Gastroenterol 22, 9880-9897.

62. European Association for Study of Liver \& Asociacion Latinoamericana para el Estudio del Higado (2015) EASL-ALEH Clinical Practice Guidelines: non-invasive tests for evaluation of liver disease severity and prognosis. J Hepatol 63, 237-264.

63. Prati D, Taioli E, Zanella A, et al. (2002) Updated definitions of healthy ranges for serum alanine aminotransferase levels. Ann Intern Med 137, 1-10. 